\title{
Context matters: The value of analyzing human factors within educational contexts as a way of informing technology-related decisions within design research
}

(

MacKinnon (Kim), International Journal of Computer-Supported Collaborative Learning, 2012, DOI: $10.1007 / \mathrm{s} 11412-012-9149-9$.

Abstract While design research can be useful for designing effective technology integrations within complex social settings, it currently fails to provide concrete methodological guidelines for gathering and organizing information about the research context, or for determining how such analyses ought to guide the iterative design and innovation process. A case is described, in which the author explores one way that researchers might go about systematizing the analysis of contextual influences within a design research study. It borrows a method from engineering called "Cognitive Work Analysis" (CWA) (Vicente, 1999), to methodically study the impact of political, organizational, team, psychological, and physical factors within an initial teacher education setting. The study illustrates how a modified CWA was helpful in making contextual information more explicit and organized. Important information in the form of human factors "constraints" were identified through the CWA, providing valuable details about context that might otherwise be overlooked during design research cycles or within the reporting process.

\section{Keywords design research * technology integration *CSCL * human factors}

\section{Introduction}

A large number of technology-related research studies in the area of the learning sciences employ design research methodologies. Typically, in such studies, researchers describe and take into account contextual factors when designing technological supports for learning. Unfortunately, design research offers few methodological guidelines about how descriptions of the learning context ought to be developed and reported. As a result, it is often unclear how specific information about the learning context relates to design decision-making and its outcomes for technology-supported learning. This is a serious methodological concern, since the validity and reliability of design research relies heavily on the richness of qualitative descriptions. Without having rich information about context to inform the use of technology, it is difficult to argue that CSCL researchers are doing anything beyond ad-hoc design. The potential for mobilization of computer-supported learning innovations will depend, in part, on the 
comparability of learning contexts; how their similarities and differences may be leveraged to support re-design and improve outcomes. Therefore, this paper describes a case study that explores one way that design researchers might gather and report on information about learning context. It adapts a method from the engineering sciences called "Cognitive Work Analysis" to study the impact of political, organizational, team, psychological and physical factors within a design research project concerned with initial teacher education.

\section{Background}

Over the past two decades, design research has commanded considerable attention in the learning sciences community, due in large part to a desire to better connect research and practice (Collins, 1999). Until the mid-1970's, research on teaching and learning was predominately carried out by traditional experimental researchers in laboratories (Brown, 1992). Findings from this research were often far removed from the complexities of classroom life, and therefore bore little obvious relevance to the concerns of practitioners. Collins (1999) argues that, "Learning in the real world occurs in complex social situations, and laboratory methods of studying learnings so fundamentally alter the conditions of learning that it is not clear what to conclude from any such study" (p. 289). According to Brown (1992), shifts within the realm of cognitive research towards increasingly active models of learning (e.g., metacognition) contributed to a gradual gathering of interest in contextualized settings (e.g., classrooms) rather than decontextualized settings (e.g., a laboratory), for carrying out research. This necessitated changes in the ways that research was carried out. For some, it meant the adoption of increasingly qualitative methods of study such as ethnography, case study, grounded theory, and phenomenology. However, design research offered an alternative, one that was better aligned with teachers' and researchers' desires to actively design and refine new pedagogies and tools.

\section{Design Research Methodology}

According to Bereiter (2002), design research is not defined by a particular methodology (e.g., qualitative versus quantitative). Rather, design research is characterized by its purpose, which is "sustained innovation". For Bereiter, design research is characterized by four things:

1. Design research involves working with designers, as part of the design process.

2. Rather than adopting a completely objective stance towards the research by distancing oneself from the process that is being studied (as is typically done in traditional psychological research), design researchers immerse themselves in the context, and deliberately try to make something happen. In other words, design researchers purposefully attempt to affect their outcome rather than trying to separate their influence on it.

3. Design research is geared towards solving an existing problem, which is specific to a particular community of practice.

Author's Accepted Pre-print Version MacKinnon (Kim), International Journal of Computer-Supported Collaborative Learning, 2012, DOI: 
4. Design research is guided by goals that emerge as part of the design process. Research goals may change throughout the course of a study, through iterative cycles of design and research.

Collins (1999) provides a list of seven criteria with which to compare design research to more traditional psychological experimental methodologies. The following list of Collins' criteria is adapted from Woodruff and Nirula (2005):

\section{Laboratory setting versus a messy situation}

Design research is typically carried out in complex social settings, such as classrooms, rather than in laboratory settings.

\section{Single dependent variable versus multiple dependent variables}

While laboratory research typically isolates one dependent variable as the focus of study, in design research there may be multiple variables of interest in the study.

\section{Controlling variables versus characterizing the situation}

In laboratory research, the investigator normally attempts to control for the number of variables influencing outcomes in the study, whereas in design research, the investigator abandons this control in favor of rich and elaborate descriptions of the complexity of the context.

\section{Fixed procedures versus flexible design revision}

In an experimental methodology, procedures for the study are normally indicated up front and strictly adhered to through the course of the investigation. In a design research study, the investigator may change the direction of the study while it is in progress in response to contextually situated and emerging needs within the research setting.

\section{Social isolation versus social interaction}

In traditional laboratory research, the investigator typically takes on the role of an outside observer, whereas in design research the investigator participates fully in the context of the study. Furthermore, participants in a design study typically have some influence on the directions of the investigation.

\section{Testing hypotheses versus developing a profile}

In a traditional experimental study, the investigator normally sets out to 'prove' or 'disprove' a particular hypothesis or set of hypotheses whereas, in design research the investigator intentionally tries to 'make something happen', within a particular context; the investigator does not attempt to generalize their conclusions.

\section{Experimenter design and analysis versus co-participant design and analysis}

In a traditional experimental study, the problem or focus of the investigation is normally determined by the researcher, whereas in a design research study, the focus of the study 
normally addresses some problem that is specific to the context, and that is of particular importance to the participants; the researcher and the participants take on the role of codesigners of the study.

There are many benefits to design research, for both researchers and practitioners including: 1) Increased relevance: For the practitioner, the contextual situatedness of the research makes it more likely to be directly useful for teaching, and therefore making it more likely that the researcher's work will find value beyond academic prose; 2) Convergence of expertise: The co-participant relationship between researcher and practitioner focuses their combined efforts on professional meaning-making and knowledge advancement as opposed to dividing their efforts;

3) Sustained progress: The iterative design cycle helps ensure that ideas about best practice continue to expand and improve over time, rather than being reduced to a set of quickly outdated methods to be enacted.

\section{Problems with Design Research}

There is a constant tension between designing an exciting classroom for happy campers and maintaining research standards of control and prediction (Brown, 1992, p. 173).

The above quote captures one of Ann Brown's (1992) main arguments about conducting design research (or "design experiments"): that, for research conducted in ordinary learning contexts such as classrooms - there is often a trade off between the kind of experimental control that is necessary to make generalizable conclusions, and the desire to generate research conclusions that are likely to have some direct implications for issues pertaining to practice. In traditional psychological (or experimental) research, studies are typically carried out in research labs, with a single individual, and the investigation is structured to focus on a variable that has been carefully isolated to ensure that data has not been contaminated, and that the resulting conclusions have not been drawn upon confounding, mediating factors. More recently, educational design research has centered on studies that are situated within real classrooms, with groups of students, and the investigation is structured around a problem related to practice. Therefore, the investigation is deeply embedded within the context being studied, and as a result many variables come into play.

According to Brown (1992), the shift in location of research from lab to classroom has also led to an increased interest in context. However, as Brown points out, "it is a nontrivial task to capture the rich social and intellectual life of a classroom" (p. 163) and "components are rarely isolatable" which "presents a methodological headache for traditional psychology, allergic as it is to multiply confounded experiments" (p. 166). This inability to "unconfound" (Brown, 1992) one variable from another is not specific to design research alone; it is generally an attribute of qualitative research more broadly. However, for design researchers the consequences of the unknowns can greatly amplify the risk of researchers overcompensating for this uncertainty with overly large and unmanageable data sets, and/or to "project creep" as more and 
more variables are included over time into the research design (Baek, Hjalmarson, BannanRitland, 2008; Dede, 2004). When design research involves technology, technological innovations can inherit these problems - trying to address too much, and subsequently supporting very little.

Researchers have identified other challenges associated with design research, such as: 1) Time costs: Design research takes time; time for the researcher to sufficiently acquaint themselves with a context, time in which to engage in aspects of design and re-design, and time to evaluate the impacts of each iteration; 2) Uncertainty: Since design research takes place in socially complex contexts (authentic learning contexts), there are often unforeseen problems or activities that can emerge throughout the course of a study, which would be difficult for the researcher to predict a priori. Therefore, the design researcher must have a certain tolerance for the unknown; and 3) Lack of generalizability: Design research projects often make use of a mixture of methodologies, both qualitative and quantitative (Reichardt \& Cook, 1979). This is also referred to as a "mixed-method", where quantitative data can be used to increase the validity, interpretability, depth or scope of qualitative findings (Greene, Caracelli \& Graham, 1989). However, in these instances, quantitative data is not typically used to justify general claims as it would in a traditional experimental design. The fact that design research is carried out in complex social contexts often precludes the researcher from claiming that a particular construct was not confounded by other mediating factors - factors that are also often difficult to identify and isolate (Brown, 1992).

\section{Implications of Design Research for Technology Integration}

While both traditional experimental studies and design research might be concerned with the impact of technology for learning, design research allows co-participants to develop better ways of using technology over time, within a particular context. For a traditional experimental researcher, a technology-based intervention is likely to be fairly narrow in focus, controlled for contextual variability, and place emphasis on causal outcomes. While findings from these types of studies are usually well defined and very specific, they tend to be more ideally suited to the drawing of broad conclusions about technology implementation, such as 'use versus non-use'. For example, a quasi-experimental study might show that the use of one-to-one laptops in classrooms, to support access to information online, on average can lead to higher levels of content understanding in comparison to classrooms without access to the technology. However, what the experimental study cannot say for certain is how the technology ought to be used to support learning within a specific context. Design research on the other hand, provides an opportunity for co-participants to refine strategies for integrating technology toward a desired end state, increasing the likelihood that outcomes will ultimately have some value within the context.

While design research is much more sensitive to the nuances of context than traditional experimental approaches, it is arguably far less structured in terms of prescribed methodologies. In particular, design research fails to offer any structures or methods that could guide educational researchers in the systematic gathering and reporting of information about situational factors. Thus, some design research studies inevitably conduct a more thorough analysis of contextual 
issues than others. If it were possible to develop methods that researchers could use to more systematically gather and report on information about the learning context, researchers might be better aware of the constellation of influences at play in the educational environment and its surroundings. In the next section of the paper, Cognitive Work Analysis (CWA) is presented as a potentially useful method to address this shortcoming.

\section{Cognitive Work Analysis: A Framework for Analyzing Contextual Factors}

According to engineer Kim Vicente (2003), the world is currently experiencing a period of technological chaos, or a mismatch between technological innovation and current human social structures. This mismatch has become increasingly apparent in education, where some would suggest that technology has failed to support any substantial change in the way that learning happens in school settings (Cuban, 2001; 1986). Vicente suggests that there are three reasons for this technological chaos: 1) technology is "frequently too complex for people to manage", 2) "'softer' aspects of technological systems (work schedules, team coordination, and so on) can also make people's lives more difficult", and 3) problems between people and technology are continuing to get worse, not better (p. 33). For Vicente, the way out of the current state of chaos is to find a solution in which social and technological structures are better linked together, in order that a better quality of life may be achieved (i.e., one in which fewer problems occur).

\section{Affordances and Constraints}

Knowing how to effectively integrate technology into learning environments requires an understanding of context. In this way, the value added of technology can be thought of as an "affordance relationship", to the degree that a particular technology and what it affords comes together with what is needed within a particular learning environment. Gibson (1986) wrote about the concept of an affordance, suggesting that it is distinct from the term 'afford'. According to Gibson, any medium, substance, surface, object, etc. can afford certain things but its affordance depends on an actor - someone or something taking action - in relation to it. In other words, an affordance "implies the complementarity of the animal and the environment" ( $p$. 127). For example, a stick may serve as a bridge, affording the ability to cross from one side of a riverbank to another. However, the stick being small and brittle may only serve as an affordance to a small creature like an ant or a squirrel, not a human being that is relatively heavy and likely to break the stick upon standing on it. In other words, the stick is an affordance to the ant or the squirrel, but not the human. Norman (1988) would add that the affordance of the tool also depends on the actor's perception of the object in relation to a desired goal; for the human, the stick is not a bridge, but maybe kindling for the fire.

Vicente (2003) suggests a similar interactional relationship between people and technology, which he calls a "Human-Tech" relationship. However, Vicente adds that interactions between humans and technology often take place in complex settings (such as work environments) and therefore behaviour is also situated within an ecology of factors - or what Vicente calls "constraints". Action is not simply a matter of an individual's behaviour or makeup in relation to a particular tool, but also of social structures that are embedded within the larger 
context, in which individual actions are taking place. What this implies is that affordances are not inherent in tools themselves, and is it insufficient to define an affordance as isolated interactions between a person and a tool. Rather, an affordance is a dynamic concept that can only be understood in relation to context.

\section{Identifying Relevant Human Factors through Cognitive Work Analysis}

For Vicente (2003), the first step in any good design innovation is to identify a problem worth solving. In education, one such problem is to find better ways of supporting learning in educational contexts that have quickly become increasingly technological places. However, the exact form that this problem will take will depend on the specific educational context being examined.

The next step, in what he refers to as a "Human-Tech" process, is to uncover the human factors that will be relevant to design. Cognitive Work Analysis (CWA) (Vicente, 1999) supports the creation of technological solutions that are informed by the unique attributes of the human social systems for which these solutions are to be used. In education, these "systems" could include contexts such as: individual classrooms, schools, universities and colleges, and program departments. Attributes - or "constraints" as they are called in CWA - include things such as: the functional purpose of the system (e.g., why the system exists, what it was designed to do), the organizational goals of the system (e.g., visions and objectives for the system as a whole), individual capabilities of "stakeholders" in the system (e.g., skill requirements, training) and their perceptions of their role in the system, and the day-to-day kinds of work that are typically carried out within the system (e.g., in order to accomplish organizational objectives).

CWA was developed as a technological design tool emerging from the more traditional "hard" science fields of engineering, aviation, medicine, and ergonomics (Rasmussen, Pejtersen \& Goodstein, 1994). More recently, it has been expanded by Vicente (1999) and has begun to appear in the "social" sciences (Fidel \& Pejtersen, 2004) and specifically, in the learning sciences (MacKinnon, 2008; 2006; MacKinnon \& Woodruff, 2008a; 2008b; 2008c; Nirula \& Woodruff, 2008). CWA is typically carried out through extensive data collection procedures such as observations, documentation analysis (review of key documents), informal conversations with stakeholders, and extended interviews with key stakeholders, prior to initiating design. All data is then merged and used to support analysis of the relevant human factors ("constraint analysis"), which is then used to support socio-technical design for the particular system of interest (i.e., the one in which the CWA was carried out).

Other than this article, the most extensive accounts of CWA can be found in a report by Naikar, Hopcroft and Moylan (2005) in which the authors focus on an analysis of the work domain component of the CWA model, and a dissertation thesis by Nirula (2008), which looks at the application of CWA in an elementary school context. The current research represents the only known application of CWA within a teacher education context.

Vicente's (1999) writing on CWA, which elaborates on the difference between CWA (which he refers to as a "formative work analysis") and other types of work analysis, suggests the following important caveats regarding technological design: 
That behaviour in a work system is situated in a context. Work is always carried out in some particular work context, and therefore design should bear that context in mind. Good design will recognize the limitations of assuming a 'one size fits all' approach.

The context-conditioned variability of work. Not only is work understood to be bound to a particular context, it is also acknowledged that conditions of that context can change. In particular, in open, complex social systems, in which conditions can vary - such as a learning context - needs, problems and goals of the work system can change and evolve in ways that cannot always be predicted.

There are intrinsic aspects of work. There are often elements of a work context that are not directly observable in its current practices, but nevertheless have an impact on behaviour. These intrinsic constraints delimit the currently unexplored possibilities for work-related design. In complex social systems, Vicente argues that intrinsic aspects of work should be given primacy of concern for designers, rather than cognitive - or psychological - factors (although he acknowledges that these are also important to design).

That behaviour evident in current practice is not always directly related to goals of the work system. There are often aspects of current work practices that have little direct relationship to carrying out the goals of the work system, yet they may serve some adaptive purpose. These "workarounds" often help to identify potential areas of improvement for the work system.

For Vicente (1999), it is the last two points that distinguish CWA from other types of work analyses such as Task Analysis (e.g., Gagne \& Briggs, 1979) or Activity Theory (Kaptelinin \& Nardi, 2006) (which is called a "descriptive approach"). Vicente (1999) points out that CWA shares some of the qualities of the aforementioned work analyses (such as the contextconditioned variability assumed with descriptive work analyses), however CWA's distinction lies in its ability to also "design for adaptability" by revealing the inherent aspects of a work (or learning) system ("intrinsic constraints") that are not necessarily apparent in its current practices, but nevertheless have an impact on the 'boundaries on action' for individuals in the system. In this respect, CWA is a suitable process for supporting design research; arguably, innovations are more likely to be successful if the context in which those innovations are to be integrated can be more deeply understood.

\section{A Case Study Application of Cognitive Work Analysis in Education}

The case study that follows in this paper describes a design research project in which CWA was used to support technology integration in the context of a two-year teacher education program. The goal of the design research was to determine how an online computer-supported collaborative learning environment could be meaningfully integrated into a two-year graduate level teacher education program. 
The focus of the remainder of this paper is to document the procedure involved in carrying out the CWA, and to report on the results of the human factors constraint analysis and it's design implications. In general, the CWA procedure can be thought to include two phases that precede design experimentation: data collection and analysis of constraints, and review of constraints (i.e., making decisions about which constraints will be addressed and their design implications). The design implications will depend in part, on the overall problem guiding the design work (i.e., what am I trying to accomplish?). Once design implications are established, specific strategies can be put into action and examined (Fig. 1).

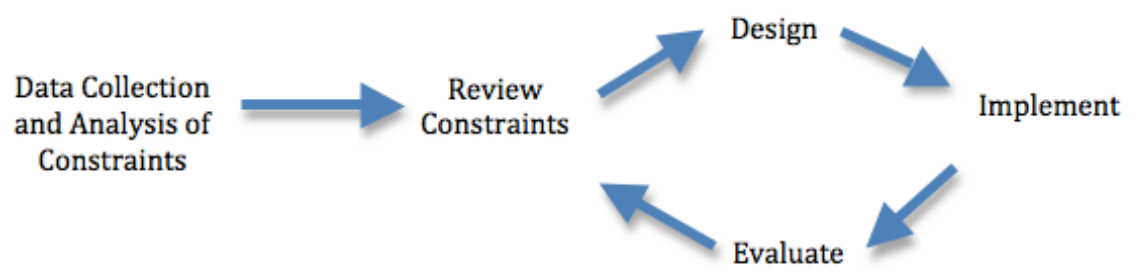

Figure 1. Prototypical Illustration of a CWA-Informed Design Process

\section{Overview of the Research Study}

The design research project took place over a three-year period (2005-2008). In September 2005, the researcher began informal observations and discussions with stakeholders in a graduate level teacher education program located within a large, urban university in Ontario. During this time, the researcher developed an overall sense of the program and was able to identify that there was a major problem with its research component. In particular, many students felt that the major research project (a significant component of the second year in the program) was undervalued and under supported, and this was echoed to some degree by faculty concerns about the quality of the research projects. The issue of supporting teacher candidates in carrying out classroombased research as part of their initial teacher training became the primary problem focus for the design study.

In June of 2006, the researcher began the CWA process, including extended, semistructured interviews with key stakeholders in the program (students, faculty, and senior administration) to find out more about the program, and the particular factors that might be contributing to problems with the major research project (MRP). At this time, there were no examples of CWA interviews that had been used in an educational context. Therefore, the interview questions were developed in consultation with a larger research group interested in the application of CWA to Education. Vicente's book on Cognitive Work Analysis (1999), Naikar, Hopcroft and Moylan's (2005) report on Work Domain Analysis, and the five Human-Tech 
categories offered by Vicente (2003), were the primary supportive materials used to create the list of questions. These questions targeted things such as: stakeholders' everyday experiences in their program, how they see their role in the program, their goals and priorities within the program, people they typically interact with, and tools they typically use to carry out their work. Each interview lasted approximately 45 to 75 minutes. Due to challenges with getting access to key stakeholders between May and August, it was necessary to extend the interview process into the fall of the second year of the study. By the middle of the 2006-2007 academic year, the researcher was able to develop a complete draft of the human factors constraint analysis (identification of the human factors relevant to design). These constraints were later verified to ensure that the constraint descriptions - or summaries - made sense with the raw data, and underwent an inter-rater process to ensure that the constraint categories could consistently be matched to a constraint description. By the fall 2007, the initial draft of the constraint analysis was revised where applicable, and completed. In the 2007-2008 academic year, iteration 2 of the design study began using the same constraints that were targeted in iteration 1 . Two new constraints that had emerged during the 2006-2007 academic year (i.e., constraints that had not been identified through the original CWA procedure) were also added to the list.

\section{Research Context}

This research took place in the Faculty of Education at a large urban university in Canada. The design research focused on the major research project (MRP) component of a two-year consecutive Master of Teaching (MT) program. At the time of the study, the MT program was a Primary-Junior (PJ), and Junior-Intermediate (JI) teacher preparation program, and it was relatively small in comparison to other Bachelor of Education programs (eight month consecutive and five year concurrent). The small size of the MT program made it a relatively ideal - and manageable - context in which to explore the application of CWA. As Table 1 summarizes, in the first year of this study there were 65 MT students (41 first year students, and 24 second year students), and in the second year of the study there were 82 students (41 first year students and 41 second year students). The MT program has a cohort-based design, meaning students are organized into groups (in this case, approximately 10-20 students in each cohort) and they take the majority of their classes together over the two-year period of the program.

Table 1

Summary of Participation (Second Year Students and Faculty) in the Research

\begin{tabular}{|c|c|c|c|c|}
\hline 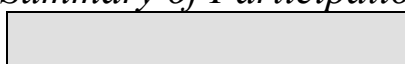 & \multicolumn{2}{|c|}{ 2006-2007 Academic Year } & \multicolumn{2}{|c|}{ 2007-2008 Academic Year } \\
\hline & No. & $\%$ & No. & $\%$ \\
\hline $\begin{array}{l}\text { Total second year } \\
\text { students }\end{array}$ & 24 & 100 & 41 & 100 \\
\hline Total faculty & 9 & 100 & 12 & 100 \\
\hline $\begin{array}{l}\text { No. of students who } \\
\text { agreed to participate in } \\
\text { the CWA interviews }\end{array}$ & 8 & 33 & NA & NA \\
\hline
\end{tabular}

Author's Accepted Pre-print Version MacKinnon (Kim), International Journal of Computer-Supported Collaborative Learning, 2012, DOI: 


\begin{tabular}{|l|l|l|l|l|}
\hline $\begin{array}{l}\text { No. of faculty who } \\
\text { agreed to participate in } \\
\text { the CWA interviews }\end{array}$ & 6 & 67 & NA & NA \\
\hline
\end{tabular}

At the beginning of the design research, there was some technology that was already in use in the program, such as email and discussion boards. In general, the MT program had adopted an infusion model to technology integration (technology is integrated into all courses, as opposed to a stand-alone course) however, the use of technology varied from instructor to instructor from no use, to full integration (Rowley, Dysard \& Arnold, 2005). According to informal discussions with students and faculty prior to the formal constraint analysis, MT students had historically experienced difficulty with conducting the major research project component of their program. Consequently, it was decided to conduct a design research study to explore how this problem might be addressed.

\section{Data Collection that Supported the CWA}

The following sections describe each of the types and purposes of data collected during the research study.

Documentation Analysis. The researcher was given access to annual MT program documents including: timetables, lists of instructors, student expectations, course outlines, course curriculum, assignment descriptions as well as copy of the most recent Ontario College of Teachers accreditation proposal for the program. The researcher also had access to public documents such as: the MT program website and the university bulletin describing the program, its admission criteria, and program expectations.

Stakeholder Interviews. In June of 2006, the researcher began conducting the formal CWA interviews. Students and faculty members - two, who also held senior administrative positions for the MT program - were asked a series of questions about the program and their role within it. Each interview followed a semi-structured format, and lasted approximately 45 to 75 minutes. The interviews were digitally recorded, with the consent of the interviewees, so that they could later be transcribed for analysis purposes.

Questionnaires. The researcher distributed two student questionnaires: one at the beginning of the 2006-2007 academic year, and one at the beginning of the 2007-2008 academic year. Parts of the questionnaire that pertained to technological competencies were based on a survey developed by Ross, Hogaboam-Gray and Hannay (1999), and parts of the questionnaire that pertained to beliefs about the use of technology in teaching were based on a survey developed by Brush, Glazewski, Rutowski, Berg, Stromfors et al. (2003). These questionnaires were used to triangulate information from other data sources (such as the interviews) pertaining to things like: students' experiences in the program, their prior experiences with technology and their prior experience with carrying out 
research. Furthermore, the questionnaire administered at the beginning of the year in 2007-2008 also included a series of questions which were used to: 1) provide support for the comparability of the student cohorts between 2006-2007 and 2007-2008, and 2) as an added measure to verify the continued relevance of the human factors constraints that pertained directly to the design study.

Faculty were also given a questionnaire at the beginning of 2006-2007 to triangulate information gathered from other data sources about the program, their experiences with using technology in their teaching, and their prior experiences with supervising the MT student research projects.

Observations and Field Notes. Throughout the study, the researcher made observations and conducted informal conversations with various stakeholders, which were recorded in the researcher's field notes. Observations and informal discussions were used to support: 1) triangulation of other data sources used to generate the human factors constraint analysis, 2) record ongoing discussions with the primary faculty co-participant in the design study (the Psychology instructor in the program), 3) record information about any new constraints that emerged throughout the design study, and 4) record information about the outcomes of the design study.

\section{Content Analysis of Stakeholder Interviews and Other Data Sources}

The student interviews were transcribed, and then verified by someone other than the transcriber to ensure the correctness of the audio-to-print translation. The transcripts were then used to perform a content analysis using the five Human-Tech constraint categories proposed by Vicente (2003) - political, organizational, team, psychological and physical. The transcripts were first coded using NVIVO v2.0 (C QSR International). Once each transcript was fully coded, the researcher ran a search report for each of the five categories ("nodes") and these excerpts were used to create a 'constraint analysis table'. The first column of the table indicated the category to which the interview excerpt was assigned. In the second column, each constraint was given a 'constraint description', consisting of approximately one or two sentences. The third column of the table indicated the data sources that were used to support the creation and assignment of the constraint.

The researcher conducted two external verifications on the human factors constraint analysis ("constraint analysis"): first, an audit was performed on the human factors constraint analysis and second, an inter-rater assessment was performed on the assignment of the constraint descriptions to a constraint category. Verification procedures also included a member check on the student constraints that had direct design implications in the study.

\section{Cognitive Work Analysis Findings}

Author's Accepted Pre-print Version MacKinnon (Kim), International Journal of Computer-Supported Collaborative Learning, 2012, DOI: 
Two questions guided the application of the CWA: 1) What constraints are revealed about the MT program? and, 2) What are the design implications of the constraints, for supporting student research in the MT program?

Once verification procedures for the content analysis of the CWA data had been completed and adjustments had been made to satisfy any auditor-researcher and/or raterresearcher disagreements, there were a total of 358 human factors constraints identified in the context of the two-year MT program. Using Vicente's (2003) Human-Tech categories as a framework for the content analysis, 30 human factors were found to pertain to political constraints, 100 pertained to organizational constraints, 82 pertained to team constraints, 125 pertained to psychological constraints, and 21 pertained to physical constraints. Faculty and student data was analyzed separately and then merged into one human factors constraint table. Table 2 summarizes the distribution of the constraints across each group.

Table 2

Summary of Human Factor Constraints Identified in the MT Program

\begin{tabular}{|l|c|c|c|}
\hline & Faculty Data & Student Data & Totals \\
\hline Political & 25 & 5 & 30 \\
\hline Organizational & 92 & 8 & 100 \\
\hline Team & 66 & 16 & 82 \\
\hline Psychological & 102 & 23 & 125 \\
\hline Physical & 15 & 6 & 21 \\
\hline TOTAL & $\mathbf{3 0 0}$ & $\mathbf{5 8}$ & $\mathbf{3 5 8}$ \\
\hline
\end{tabular}

Although it appears that the faculty data had nearly six times the number of constraints, it should be noted that there was a lot of overlap between the student data (i.e., students having similar responses). In contrast, there was a lot of variability in responses given by faculty, making it more difficult to compile results into a single constraint description. Therefore, the higher number of faculty constraints represents the complexity and range of instructor responses about the overall structure of, and activity within, the MT program.

Design Implications of the Human Factors Constraints for CSCL

Although all of the human factors constraints identified are likely to have an impact to some degree on any technological design, the researcher decided to focus only on a small number given the scope of the research, and based on what could reasonably and meaningfully be addressed within a single design study. In total, 14 of the faculty constraints, and 10 of the student constraints were addressed ( 6 organizational constraints, 5 team constraints, and 13 psychological constraints). While these constraints only represent approximately $6.7 \%$ of the total constraints originally identified through the CWA, they were critical ones that had direct implications for thinking about how to integrate an online computer-supported collaborative learning tool. Two more psychological constraints emerged through the initial implementation of 
the design in iteration 1, and these were subsequently added to list of constraints being addressed in iteration 2. These constraints are summarized in Table 3, including a description of their implications for thinking about how to meaningfully integrate an online computer-supported collaborative learning tool.

Table 3

Constraints Addressed in the Design Study

\begin{tabular}{|c|c|c|}
\hline & Description of constraint & Possible implications for design \\
\hline \multicolumn{3}{|c|}{$\begin{array}{l}\text { Organizational Constraints (Program priorities and expectations, course expectations, } \\
\text { admission criteria, scheduling, job descriptions, incentives/disincentives) }\end{array}$} \\
\hline 1 & $\begin{array}{l}\text { There is an expectation that the students } \\
\text { will complete their data collection during } \\
\text { their first teaching placement in the } \\
\text { second year of the program. }\end{array}$ & $\begin{array}{l}\text { CSCL Implication }(s) \text { : An online forum } \\
\text { could be used to keep students connected } \\
\text { to research support while they are on } \\
\text { practicum. }\end{array}$ \\
\hline 2 & $\begin{array}{l}\text { Although many of the faculty that teach } \\
\text { the Year 2's have elements of research in } \\
\text { their courses, there's not officially "a } \\
\text { research course" during the second year of } \\
\text { the program. }\end{array}$ & $\begin{array}{l}\text { CSCL Implication }(\mathrm{s}) \text { : An online forum } \\
\text { could provide a space to get research- } \\
\text { related support. }\end{array}$ \\
\hline 3 & $\begin{array}{l}\text { Exploring the use of technology in } \\
\text { teaching is one of the major components } \\
\text { of the MT program. }\end{array}$ & $\begin{array}{l}\text { CSCL Implication }(s) \text { : Use of technology } \\
\text { in teaching is a program priority. }\end{array}$ \\
\hline 4 & $\begin{array}{l}\text { Students are expected to conduct the } \\
\text { literature review, data collection and } \\
\text { write-up for their research projects during } \\
\text { the second year of the program. }\end{array}$ & $\begin{array}{l}\text { CSCL Implication(s): An online forum for } \\
\text { research support would likely be most } \\
\text { useful to second year students. }\end{array}$ \\
\hline 5 & $\begin{array}{l}\text { Students are required to use technology to } \\
\text { complete coursework, and as a program } \\
\text { communication tool. }\end{array}$ & $\begin{array}{l}\text { CSCL Implication(s): Students will } \\
\text { already have some experience with } \\
\text { communication technology in their } \\
\text { program. }\end{array}$ \\
\hline 6 & $\begin{array}{l}\text { There is not a lot of time or opportunity } \\
\text { built into the program for students to } \\
\text { engage in independent study or carry out } \\
\text { their research projects. }\end{array}$ & $\begin{array}{l}\text { CSCL Implication(s): An online forum } \\
\text { could give students access to "just-in- } \\
\text { time" research support. }\end{array}$ \\
\hline
\end{tabular}

Author's Accepted Pre-print Version MacKinnon (Kim), International Journal of Computer-Supported Collaborative Learning, 2012, DOI: 


\begin{tabular}{|c|c|c|}
\hline & Description of constraint & Possible implications for design \\
\hline 7 & $\begin{array}{l}\text { There is some indication that there is a } \\
\text { lack of consensus among faculty, } \\
\text { regarding who would be supervising } \\
\text { students, and whether formal supervision } \\
\text { was actually needed. }\end{array}$ & $\begin{array}{l}\text { CSCL Implication }(s) \text { : An online forum } \\
\text { could provide a reliable space for students } \\
\text { to access support, as needed. }\end{array}$ \\
\hline 8 & $\begin{array}{l}\text { The amount of help students need with the } \\
\text { research varies during the year, and also } \\
\text { between students, but there are times } \\
\text { when there will be a flurry of contact with } \\
\text { students, when they feel uncertain about } \\
\text { details of their research, or when they are } \\
\text { under the pressure of time to complete the } \\
\text { research. }\end{array}$ & $\begin{array}{l}\text { CSCL Implication(s): Students may access } \\
\text { the online forum for research support at } \\
\text { different times; some times will be busier } \\
\text { than others. }\end{array}$ \\
\hline 9 & $\begin{array}{l}\text { Students often have little contact with the } \\
\text { university and their cohort peers during } \\
\text { practicum. }\end{array}$ & $\begin{array}{l}\text { CSCL Implication(s): An online forum } \\
\text { would give students access to their peers } \\
\text { and the university at a time when many } \\
\text { are collecting research data. }\end{array}$ \\
\hline 10 & $\begin{array}{l}\text { Students often look to each other for } \\
\text { support and advice. }\end{array}$ & $\begin{array}{l}\text { CSCL Implication(s): An online forum } \\
\text { would allow students to connect with one } \\
\text { another, and collaborate around common } \\
\text { problems there are experiencing with the } \\
\text { research projects. }\end{array}$ \\
\hline 11 & $\begin{array}{l}\text { There is some indication that associate } \\
\text { (partner) schools do not always fully } \\
\text { support the students in carrying out their } \\
\text { research, despite the fact that they've } \\
\text { agreed to do this as part of their role. }\end{array}$ & $\begin{array}{l}\text { CSCL Implication(s): An online forum } \\
\text { could provide a space where students can } \\
\text { receive advice on things like how to } \\
\text { acquire research participants. }\end{array}$ \\
\hline \multicolumn{3}{|c|}{$\begin{array}{l}\text { Psychological Constraints (Personal competencies, understanding, priorities, skills, } \\
\text { feelings) }\end{array}$} \\
\hline 12 & $\begin{array}{l}\text { One of F1's (instructor co-participant) } \\
\text { personal priorities for her teaching is to } \\
\text { make sure that her assignments and the } \\
\text { major ideas she covers are integrated with } \\
\text { other aspects of the program. }\end{array}$ & $\begin{array}{l}\text { CSCL Implication(s): F1's course would } \\
\text { be a good place to introduce the students } \\
\text { to the online forum. }\end{array}$ \\
\hline 13 & $\begin{array}{l}\text { F1's (instructor co-participant) believes } \\
\text { that learning happens by interacting with } \\
\text { others, and through discussion. }\end{array}$ & $\begin{array}{l}\text { CSCL Implication(s): F1's course would } \\
\text { embrace a CSCL approach to learning. }\end{array}$ \\
\hline
\end{tabular}

Author's Accepted Pre-print Version MacKinnon (Kim), International Journal of Computer-Supported Collaborative Learning, 2012, DOI: 


\begin{tabular}{|c|c|c|}
\hline & Description of constraint & Possible implications for design \\
\hline 14 & $\begin{array}{l}\text { F1's (instructor co-participant) believes it } \\
\text { is important to have other graduate } \\
\text { students involved in the MT program. She } \\
\text { thinks both the graduate students and the } \\
\text { MT students benefit from learning from } \\
\text { each other. }\end{array}$ & $\begin{array}{l}\text { CSCL Implication(s): Possibility to link } \\
\text { other graduate students to support } \\
\text { research through the online forum. }\end{array}$ \\
\hline 15 & $\begin{array}{l}\text { F2 claims that some students are better } \\
\text { able to carry out the research projects than } \\
\text { others. }\end{array}$ & $\begin{array}{l}\text { CSCL Implication(s): The online forum } \\
\text { could bring students with less research } \\
\text { experience together with students who } \\
\text { have more research experience. }\end{array}$ \\
\hline 16 & $\begin{array}{l}\text { According to F5, the MT students are } \\
\text { often working on their research right up } \\
\text { until the end of the year - just before } \\
\text { marks are due for faculty. }\end{array}$ & $\begin{array}{l}\text { CSCL Implication(s): An online forum } \\
\text { that provides research support will need to } \\
\text { be available all year. }\end{array}$ \\
\hline 17 & $\begin{array}{l}\text { According to F5, some faculty find it } \\
\text { challenging to deal with the demands of a } \\
\text { combination, pre-service and graduate } \\
\text { program (e.g., practicum supervision and } \\
\text { research support). }\end{array}$ & $\begin{array}{l}\text { CSCL Implication(s): An online forum } \\
\text { where students could get research support } \\
\text { may alleviate some work pressure on } \\
\text { supervisors. }\end{array}$ \\
\hline 18 & $\begin{array}{l}\text { F6 doesn't believe students are always } \\
\text { well supported (e.g., given access to } \\
\text { quality teaching, access to supervisors). }\end{array}$ & $\begin{array}{l}\text { CSCL Implication(s): An online forum } \\
\text { accessed by all students and therefore, } \\
\text { research support would be available on a } \\
\text { more reliable and consistent basis. }\end{array}$ \\
\hline 19 & $\begin{array}{l}\text { There is a perception among some } \\
\text { students that the research project is not } \\
\text { really valued in the program. }\end{array}$ & $\begin{array}{l}\text { CSCL Implication(s): An online space } \\
\text { dedicated to research support could } \\
\text { reinforce the importance of the research } \\
\text { component in the program. }\end{array}$ \\
\hline 20 & $\begin{array}{l}\text { Students perceive a disconnect between } \\
\text { elements of the program (e.g., between } \\
\text { different courses), including between the } \\
\text { research and the rest of the program. }\end{array}$ & $\begin{array}{l}\text { CSCL Implication(s): An online forum } \\
\text { could provide a space where elements of } \\
\text { the program come together with the } \\
\text { research. }\end{array}$ \\
\hline 21 & $\begin{array}{l}\text { Research skills among students in the } \\
\text { program are varied, and often limited. }\end{array}$ & $\begin{array}{l}\text { CSCL Implication(s): Online research } \\
\text { support will need to include guidance for } \\
\text { some of the basics about carrying out } \\
\text { research. }\end{array}$ \\
\hline
\end{tabular}

Author's Accepted Pre-print Version MacKinnon (Kim), International Journal of Computer-Supported Collaborative Learning, 2012, DOI: 


\begin{tabular}{|c|c|c|}
\hline & Description of constraint & Possible implications for design \\
\hline 22 & $\begin{array}{l}\text { Attempts to infuse technology in various } \\
\text { elements of the program have been seen } \\
\text { by students as an "add on", or extra work, } \\
\text { and not necessarily something that added } \\
\text { a lot of value in their learning experience. }\end{array}$ & $\begin{array}{l}\text { CSCL Implication }(s) \text { : An online forum } \\
\text { used to provide student support for a } \\
\text { major program component could be seen } \\
\text { to add value. }\end{array}$ \\
\hline 23 & $\begin{array}{l}\text { Students perceive that there is some value } \\
\text { in getting comfortable with technology, } \\
\text { and that technological skills are an } \\
\text { important competency to have for the } \\
\text { program. }\end{array}$ & $\begin{array}{l}\text { CSCL Implication(s): Opportunities to } \\
\text { learn to work with new technology is } \\
\text { valued among some students. }\end{array}$ \\
\hline 24 & $\begin{array}{l}\text { Some students enter the program with a } \\
\text { lack of experience with technology and/or } \\
\text { techno-phobic tendencies. There is some } \\
\text { resistance among students to using } \\
\text { technology. }\end{array}$ & $\begin{array}{l}\text { CSCL Implication }(S) \text { : Some students may } \\
\text { need more support in becoming familiar } \\
\text { with an online forum. }\end{array}$ \\
\hline \multicolumn{3}{|c|}{$\begin{array}{l}\text { Emergent Constraints (Constraints that were revealed after Iteration \#1 of the design } \\
\text { study) }\end{array}$} \\
\hline & $\begin{array}{l}\text { Emergent constraint apparent after } \\
\text { iteration } \# 1 \text { : } \\
\text { There are feelings of privacy among } \\
\text { students with respect to the major research } \\
\text { projects they carry out in the program. } \\
\text { They are sometimes reluctant to share } \\
\text { their research with others while it is in } \\
\text { progress, and for some students, even } \\
\text { when it is completed. }\end{array}$ & $\begin{array}{l}\text { CSCL Implication(S): Students will not } \\
\text { necessarily readily share their research } \\
\text { with others in a public online forum, and } \\
\text { may need opportunities to work in private } \\
\text { until they are ready to share their work. } \\
\text { Students may need to be encouraged to } \\
\text { eventually share their research with } \\
\text { others. }\end{array}$ \\
\hline & $\begin{array}{l}\text { Emergent constraint apparent after } \\
\text { iteration \#1: } \\
\text { Students are reluctant to take advice about } \\
\text { their research from anyone other than } \\
\text { their research supervisor. }\end{array}$ & $\begin{array}{l}\text { CSCL Implication(s): Students may not } \\
\text { readily accept research advice from others } \\
\text { (non-supervisors) in the online forum. }\end{array}$ \\
\hline
\end{tabular}

While it may be said that these constraints do not reveal anything particularly unusual or surprising, what is important is that they make discernibly explicit what is happening in the learning context, such that this information is as conspicuous as possible. Furthermore, the information is presented in a comprehensive and organized way so that the researcher is able to clearly identify the attributes that are most meaningful to the study.

\section{Criteria Used to Identify the Constraints Most Directly Meaningful to the Design Study}


While all of the constraints associated with the learning context were relevant to thinking about the integration of the collaborative online environment, the researcher used three criteria to identify the features that were most directly meaningful to the design study:

Relevancy of the constraint. The degree to which the constraint has any direct bearing on the particular problem that the researcher is trying to solve. In this case, the constraint needed to have some connection to the student research or to the use of technology in the program.

Relative importance of the constraint. The degree to which the outcome of the design study hinges on the constraint. For example, knowing that technological competencies are already valued within the program (constraint \#23) suggested that the students and faculty would likely be receptive to the possibility of using a collaborative online environment to support learning.

Likelihood of impact. The degree to which the constraint could be feasibly addressed in the design study. For example, a constraint such as the students' levels of competency with carrying out research could reasonably be taken into account in the design through the types and levels of support offered within the collaborative online environment. Whereas, it would be difficult for the researcher to have an impact on an organizational constraint, such as whether or not the student research should qualify as a full thesis. Therefore, this constraint - though relevant and potentially important to the outcome - is understood to be an attribute that is not directly manipulated by the researcher.

\section{Design Decisions Made as a Result of the CWA}

The constraints identified through the CWA were used to inform the development of an online research mentorship (ORM) program to support the MT students in carrying out their major research projects (a required component of their degree). Students were organized into small online groups, and a research mentor who was a doctoral student in the field of education oversaw each group. The mentors could be generally described as experienced researchers, and half of them were also experienced classroom teachers. The research groups gathered students together with similar research interests. Group size varied from 3 to 5 students plus one doctoral mentor.

Since the research mentorship was online, it was always available to students, allowing for "just-in-time" assistance. In the ORM, students could post questions to their mentor about the research process, get critical feedback on their research ideas, request feedback on drafts of their write up, and receive support from fellow students working on similar research problems. Furthermore, students were able to see notes posted by other students to their mentors (within their own group, and in other research groups), providing an opportunity to collaborate around aspects of the research process, and to learn from one another's experiences. 
Emergent constraints identified during the first iteration of the design study led to the redesign of the ORM, specifically to support private workspaces in the online environment, and ensure that mentorship was provided by a person whom the students were familiar with, and who was knowledgeable about the MT program and the requirements around the students' major research projects.

\section{Discussion}

This paper describes how design research can be useful for examining technology integration within complex social settings, however, there is evidence to suggest that it also fails to provide guidelines about how descriptions of the learning context ought to be developed and reported. Instead, researchers are left largely to their own devices to decide how to identify key contextual factors within their design study, and how to make this information explicit to others. This is a serious methodological concern, since important influences may be unintentionally missed possibly leading researchers to draw incorrect conclusions when explaining the success or failure of an intervention. A case study was presented, which explored one approach to systematically gather and organize contextual information within a design research study in education, through the application of "Cognitive Work Analysis" (CWA). Through this process, valuable details about the context were revealed, that might otherwise have been overlooked in the design research process.

\section{Advantages of CWA for Supporting Design of CSCL Environments}

Overall, the case study illustrated how the implementation of a modified CWA was helpful in identifying and organizing contextual information during the design research process. In the case of the initial teacher education program in which the CWA was carried out, important information in the form of political, organizational, team, psychological and physical constraints were identified. These constraints were then used to inform design decisions around technology integration in the program during a two-year design study.

While more work is needed to understand how CWA might be used to best support design research, the human factors constraint analysis offered three primary advantages for the design researcher in this case:

Informing Initial Design of the CSCL Environment. The CWA allowed the researcher to choose which design factors would be brought to the fore in the initial design iteration. These design factors were directly relevant to the context in which the CSCL environment would be used, since they were established from data collected within that context (e.g., interviews with key stakeholders, documentation analysis, observations of work carried out in the program, informal conversations). Furthermore, criteria were also established to help the researcher in making decisions about which constraints should be given priority in the design study. 
Reflecting on Design of the CSCL Environment. CWA improved the means with which to reflect on design in action, and to form new innovation strategies. In other words, the human factors constraints provided the researcher with a way to analyze which variables were likely to be impacting the design outcomes associated with the Online Research Mentorship, and to make informed choices about the direction that re-designs should take. In this respect, the application of CWA was well suited to the iterative structure of a design research methodology.

Reporting on Design of the CSCL Environment. Although this was not the focus of this paper, the constraints identified through the CWA provided a very rich source of information with which to report on the final outcomes of the design study. A rationale for successes and failures of the design could be systematically linked to information about the educational context.

Naturally, some factors within the system may remain hidden in the initial CWA procedure, only to be revealed as emergent constraints after one or more design research iterations. Nevertheless, a constraint-based approach offers design researchers a systematic way of analyzing context - one that arguably simplifies the problem of "confoundedness" in design experimentation, as originally highlighted by Brown (1992).

\section{Challenges of CWA for Supporting Design of CSCL Environments}

A primary challenge of design research is that it tends to be time- and resource-intensive, and CWA only adds to this intensity. One might question whether there are sufficient benefits gained from the added intensity of the human factors constraint analysis, particularly since the process may not reveal information that is particularly surprising or unusual about the learning context. However, what is important is that these constraints ensure that information about the learning context is made explicit in a way that is accessible to others, and that provides the researcher with some assurances that they are not overlooking important details.

Issues of time and resources involved in carrying out CWA also have implications for practice, since the need to consider context is not just a research problem. There is also a need to better understand how context can be brought to bear in making decisions about how to integrate technology into teaching from a practitioner perspective. Although there are educational technology frameworks that exist which take context into account as an important factor that needs to be considered by teachers (e.g., Koehler and Mishra's (2008) technological pedagogical content knowledge (TPCK) model), there is relatively little guidance in helping teachers understand how information about context could be organized and ultimately inform instructional design decisions with respect to technology. While the researcher does not necessarily suggest it would be feasible for teachers to engage in carrying out CWA, there are important implications that can potentially be extended to the work of teachers.

A second challenge with CWA is that it relies on having access to key stakeholders. For example, in this study the CWA could not be fully completed in advance of the first design iteration, given the teacher candidates' academic schedule. Similar problems may arise in other 
studies where persistent and reliable access to key stakeholders is difficult and time sensitive. Further research is required to better understand how to adequately address this problem, without compromising the degree of rigorousness of the constraint analysis.

\section{Conclusions}

Research suggests that there is a need to have methods for supporting technology-related decisions in educational settings that highlight the scope and importance of contextual factors for design. Although other research has indicated that context is important to understanding how to support effective ways of integrating technology into teaching and learning (Fishman, Marx, Blumenfeld, Krajcik, \& Soloway, 2004; Koehler \& Mishra, 2008; 2005), relatively little attention has been paid to how researchers (and practitioners) ought to go about organizing and reporting on contextual information in order to leverage technological affordances (Gibson, 1986; Norman, 1988).

The question 'What do CSCL technologies afford for teaching and learning?' is a physical problem. Technologies are built to do certain things, and afford certain actions. However, the question 'What are the affordances of CSCL technologies for teaching and learning?' is a Human-Tech (Vicente, 2003) problem. Although a technology may afford certain actions, its affordances are ultimately contextually bound. For design researchers, this implies a need to take seriously the problem of moving beyond the typical confoundedness of variables that exist within learning contexts, so that these affordances can be more deeply understood.

\section{Acknowledgements}

The author would like to thank Dr. Clare Brett and Dr. Jim Hewitt for reading the original version of this manuscript and providing helpful suggestions.

\section{References}

Baek, J. Y., Hjalmarson, M. A. \& Banna-Ritland, B. (2008, March). Design research on a diet: A methodological framework called design assessment. Paper presented at the annual meeting of the American Educational Researchers' Association, New York, NY.

Bereiter, C. (2002). Design research for sustained innovation. Cognitive Studies, Bulletin of the Japanese Cognitive Science Society, 9(3), 321-327.

Brown, A. L. (1992). Design experiments: Theoretical and methodological challenges in creating complex interventions in classroom settings. Journal of the Learning Sciences, 2(2), 141178.

Brush, T., Glazewski, K., Rutowski, K., Berg, K., Stromfors, C. Van-Nest, M. H., Stock, L. \& Sutton, J. (2003). Integrating technology in a field-based teacher training program: The PT3@ASU project. Educational Technology, Research and Development, 51(1), 57-72. 
Collins, A. (1999). The changing infrastructure of education research. In E. C. Lagemann \& L.S. Shulman (Eds.) Issues in Education Research: Problems and Possibilities (pp. 289-298). San Francisco: Jossey-Bass Inc., Publishers.

Cuban, L. (1986). Teachers and machines: The classroom use of technology since 1920. New York: Teachers College Press.

Cuban, L. (2001). Oversold and underused: Computers in the classroom. Cambridge, MA: Harvard University Press.

Dede, C. (2004). If design-based research is the answer, what is the question? The Journal of the Learning Sciences, 13, 105-114.

Fidel, R., \& Pejtersen, A. M. (2004). From information behaviour research to the design of information systems: The cognitive work analysis framework. Information Research, 10(1), paper 210. Retrieved from http://InformationR.net/ir/10-1/paper210.html.

Fishman, B., Marx, R. W., Blumenfeld, P., Krajcik, J., Soloway, E. (2004). Creating a framework for systemic technology innovations, Journal of the Learning Sciences, 13(1), 43-76.

Gagne, R. M. \& Briggs, L. J. (1979) Principles of instructional design (2nd ed.). New York: Holt Reinhart and Winston.

Gibson, J. J. (1986). The ecological approach to visual perception. New Jersey: Lawrence Erlbaum Associates, Publishers.

Greene, J. C., Caracelli, V. J. \& Graham, W. F. (1989). Toward a conceptual framework for mixed-method evaluation designs. Educational Evaluation and Policy Analysis, 11(3), 255-274.

Kaptelinin, V. \& Nardi, B. A. (2006). Acting with technology: Activity Theory and interaction design. Cambridge, MA: MIT Press.

Koehler, M. J. \& Mishra, P. (2005). What happens when teachers design educational technology? The development of technological pedagogical content knowledge. Journal of Educational Computing Research, 32(2), 131-152.

Koehler, M. J. \& Mishra, P. (2008). Introducing TPCK. In AACTE Committee on Innovation and Technology (Ed.), Handbook of Technological Pedagogical Content Knowledge (TPCK) for Educators (pp. 3-29). New York: Routledge.

MacKinnon, K. (2006, August). Identification of potential constraints associated with accessing and participating in Knowledge Forum ${ }^{\circledR}$ using handheld computers: A Pre-service 
Education Context. Poster presented at the annual meeting of the Institute for Knowledge, Innovation and Technology, Toronto, Ontario, Canada.

MacKinnon, K. (2008, May). A human-tech perspective on technology infusion in the context of teacher education. In C. Brett (Chair), Principled Use of Technology in Higher

Education: Are There Global Commonalities? Paper symposium presented at the annual meeting of the Canadian Society for Studies in Education, Vancouver, British Columbia, Canada.

MacKinnon, K. \& Woodruff, E. (2008a, August). Examining the potential of constraint-based technological design in supporting idea development in the context of a two-year teacher education program. Paper presented at the annual meeting of the Institute for Knowledge, Innovation and Technology, Toronto, Ontario, Canada.

MacKinnon, K. \& Woodruff, E. (2008b, March). Examining the use of Cognitive Work Analysis to inform the educational design of technology in the context of a two-year, researchbased pre-service program. Paper presented at the annual meeting of the American Educational Researchers' Association, New York, NY.

MacKinnon, K. \& Woodruff, E. (2008c). Understanding the use and misuse of technology in pre-service education through Cognitive Work Analysis. In Proceedings of the 6th Annual Hawaii International Conference on Education (pp. 217-228), Hawaii: HICE 2008.

Naikar, N., Hopcroft, R., \& Moylan, A. (2005). Work domain analysis: Theoretical concepts and methodology [Report No. DSTO-TR-1665]. Edinburgh, South Australia: DSTO Systems Sciences Laboratory.

Nirula, L. (2008). Designing constraint informed handheld-supported literacy innovations for struggling readers. Unpublished doctoral thesis, University of Toronto, Toronto, Canada.

Nirula, L., \& Woodruff, E. (2008). Innovations using Handheld Computers to Scaffold Reciprocal Teaching among Struggling Readers. Proceedings of the 6th Annual Hawaii International Conference on Education (pp. 6321-6333), Hawaii: HICE 2008.

Norman, D. A. (1988). The psychology of everyday things. New York: Basic Books.

Rasmussen, J., Pejtersen, A. M. \& Goodstein, L.P. (1994). Cognitive Systems Engineering. New York: Wiley-Interscience.

Reichardt, C. S. \& Cook, T. D. (1979). Beyond qualitative versus quantitative methods. In T. D. Cook \& C. S. Reichardt (Eds.) Qualitative and Quantitative Methods in Evaluation Research (SAGE Research Progress Series, Vol. 1, pp. 7-32). Beverly Hills, CA: Sage Publications. 
Ross, J. A., Hogaboam-Gray, A., \& Hannay, L. (1999). Predictors of teachers' confidence in their ability to implement computer-based instruction. Journal of Educational Computing Research, 21(1), 75-97.

Rowley, J. Dysard, G. \& Arnold, J. (2005). Developing a new technology infusion program for preparing tomorrow's teachers. Journal of Technology and Teacher Education, 13(1), $105-123$.

Vicente, K. (1999). Cognitive work analysis: Toward safe, productive, and healthy computerbased work. Mahwah, NJ: Lawrence Erlbaum.

Vicente, K. (2003). The human factor: Revolutionizing the way people live with technology. New York: Routledge.

Woodruff, E. \& Nirula, L. (2005). Design Research in the Elementary School Classroom. In C. Howard, J. Boettcher, L. Justice and K. Schenk (Eds.) Encyclopedia of Online Learning and Technology (Vol. II, pp. 510-517). Information Science Publishing. 